AperTO - Archivio Istituzionale Open Access dell'Università di Torino

\title{
Rapid biofilm eradication of the antimicrobial peptide 1018-K6 against Staphylococcus aureus: A new potential tool to fight bacterial biofilms
}

This is a pre print version of the following article:

Original Citation:

Availability:

This version is available http://hdl.handle.net/2318/1712866

since 2022-01-27T15:43:27Z

Published version:

DOI:10.1016/j.foodcont.2019.106815

Terms of use:

Open Access

Anyone can freely access the full text of works made available as "Open Access". Works made available under a Creative Commons license can be used according to the terms and conditions of said license. Use of all other works requires consent of the right holder (author or publisher) if not exempted from copyright protection by the applicable law. 


\section{Rapid biofilm eradication of the antimicrobial peptide 1018-K6 against Staphylococcus aureus: A new potential tool to fight bacterial biofilms}

Angelo Colagiorgi, Rossella Festa, Pierluigi A. Di Ciccio, Marta Gogliettino, Marco Balestrieri,Gianna Palmieri, Aniello Anastasio, Adriana lanieri

\section{A B S T R A C T}

Staphylococcal food poisoning - caused by certain enterotoxigenic staphylococci - is one of the most common worldwide foodborne diseases. In this context, bacterial biofilms on food processing plan surfaces can represent critical sources of contamination, being more resistant to cleaning and disinfection procedures. Therefore, it is important to prevent and control biofilm formation in food facilities. In the last years, antimicrobial peptides (AMPs) have emerged as promising biofilm contrasting tools. The recently developed AMP, named 1018-K6, revealed a significant bactericidal (MBC $10 \mu \mathrm{M})$ and biofilm-preventing efficiency $(\mathrm{MBIC} 50 \mu \mathrm{M})$ against a re- ference ATCC strain of Listeria monocytogenes and remarkable stability under different environmental conditions. In this work, a kinetic of action of 1018-K6 against two strong biofilm-producing reference strains of Staphylococcus aureus (including a methicillin-resistant $\mathrm{S}$. aureus strain) and a moderate biofilm producer en- terotoxigenic S. aureus isolated from cheese, was performed. The peptide showed an impressive rapid mode of action, eradicating established biofilms within few minutes. Bactericidal activity against planktonic cells and inhibition of biofilm formation were also observed. The significant properties of 1018-K6 make it a promising

candidate for applications in food-safety and quality control.

\section{Introduction}

Food safety is a global concern with significant implications for human health. It has been estimated from world health organization that at least 600 million people worldwide are subject annually to ill- nesses caused by unsafe food (World Health Organization, 2015).

Staphylococcus aureus is a commensal and opportunistic pathogen that can cause contamination of food products during preparation and processing (Grace \& Fetsch, 2018). It is a ubiquitous microorganism occurring on the skin and the mucous membrane of many warm- blooded animals, including human. For these reasons, food handlers are frequently implicated in transmission of such bacteria to food (Gutiérrez et al., 2012). S. aureus displays a high salt tolerance, so it can grow in ham and other meats and in dairy products. Although heat- treatment (e.g., cooking) easily kills S. aureus bacteria, some strains are able to produce enterotoxins that are resistant to heat, freezing and irradiation (Hennekinne, De Buyser, \& Dragacci, 2012). Detectable le- vels of the staphylococcal enterotoxins (SEs) are produced when the enterotoxigenic strain grows to levels $>105 \mathrm{CFU} / \mathrm{g}$, and their presence in food is responsible for the staphylococcal food poisoning (SFP), one of the most common foodborne diseases worldwide (Hennekinne, 2018). SFP symptoms usually develop within $30 \mathrm{~min}$ to $6 \mathrm{~h}$, and gen- erally include vomiting, nausea, stomach cramps, and diarrhea (Hennekinne, 2018).

The customer's awareness about chemical compounds used to con- trast the growth of spoiling and pathogenic microorganisms, led to an increasing demand for natural preservatives. In this scenario, anti- microbial peptides (AMPs) are assuming remarkable interest because of their properties and natural origin (Keymanesh, Soltani, \& Sardari, 2009). AMPs are components of the innate immune system of both prokaryotes and eukaryotes, and they are usually characterized by a broad antimicrobial spectrum activity, a low propensity for developing bacterial resistance, and a significant synergy with common anti- microbials (Palmieri et al., 2016, 2018; Wang, Zeng, Yang, \& Qiao, 2016). The activity 
of AMPs is related to their physicochemical prop- erties, e.g. amphiphilicity, net charge, hydrophobicity, and conforma- tional flexibility (Bechinger \& Gorr, 2017).

Innate defense regulator peptide-1018 (IDR-1018) is a 12-mercationic peptide (VRLIVAVRIWRR-NH2), deriving from the bovine host-defense peptide (HDP) bactenecin, found in the bovine neutrophil granules and belonged to the cathelicidin's family. IDR-1018, which has been developed by Mansour and colleagues (Mansour, de la Fuente- Núñez, \& Hancock, 2015), displays a broad-spectrum anti-biofilm ac- tivity versus Gram-negative and Gram-positive bacterial pathogens in- cluding Pseudomonas aeruginosa, Escherichia coli, Staphylococcus aureus and Salmonella Typhimurium (de la Fuente-Núñez et al., 2012; de la Fuente-Núñez, Reffuveille, Haney, Straus, \& Hancock, 2014; Reffuveille, de la FuenteNúñez, Mansour, \& Hancock, 2014).

Recently, a new 1018-derivative antimicrobial peptide named 1018- K6, in which the alanine in position 6 was replaced with a lysine re- sidue, was designed (Palmieri et al., 2018). This single point mutation was revealed to have a strong impact on the conformational status of 1018-K6, inducing an increased propensity to assume a-helix structures in membranemimetic models such as micellar solutions of SDS, dif- ferently from the parent IDR-1018, characterized by a predominant $\beta$ - sheet structure (Palmieri et al., 2018). Furthermore, 1018-K6 was able to retain its structural integrity better than IDR-1018 in a wide range of $\mathrm{pH}$ and temperature conditions for prolonged incubation times showing also a significant bactericidal and biofilm preventing activity specifi- cally against Listeria monocytogenes isolates from food-products and food-processing environments (Palmieri et al., 2018).

The present study was aimed at evaluating the antimicrobial and anti-biofilm activity of 1018$\mathrm{K} 6$ on planktonic and biofilm growth of two reference and one food-isolate strains of S. aureus in order to assess the potential use and effectiveness of this peptide in the struggle against such critical foodborne pathogen able to cause diverse life-threatening infections.

\section{Materials and methods}

\section{Materials}

Two reference strains from ATCC collection were used in this study: the methicillin-sensitive Staphylococcus aureus (MSSA) ATCC 35556, a well-known strong biofilm producer on polystyrene (Di Ciccio et al., 2015; Thompson, Abraham, \& Jefferson, 2010), and the methicillin- resistant Staphylococcus aureus (MRSA) ATCC 33591, also described as a strongly adherent strain (Gowrishankar, Kamaladevi, Balamurugan, \& Pandian, 2016). Furthermore, a S. aureus strain isolated from cheese (SA1) carrying four SEs genes (sea, sed, sej, and ser) was also included in this study.

All culture media were purchased from Oxoid (Milan, Italy) unless otherwise specified. Phosphate buffered saline (PBS) was used for washing and rinsing bacteria. The derivative 12-mer peptide 1018-K6, reproducing the IDR-1018 sequence with the replacement of the ala- nine in position 6 with a lysine residue (A6 $\rightarrow \mathrm{K} 6$ mutation) (Palmieri et al., 2018), was purchased from SynPeptide Co., LTD (Shanghai, China).

\section{Methods}

\section{Antibacterial activity assay}

The Minimum Inhibitory Concentration (MIC) and the Minimum Bactericidal Concentration (MBC) were determined by the standard broth microdilution method following recommendations of the Clinical \& Laboratory Standards Institute (CLSI, 2015). Briefly, tested bacteria cultures were cultured on Tryptic Soy Agar (TSA) at $37^{\circ} \mathrm{C}$ for $24 \mathrm{~h}$. Isolated 
colonies were inoculated in Tryptic Soy Broth (TSB), growth for $16 \mathrm{~h}$ at $37^{\circ} \mathrm{C}$ and diluted to $5 \times 105 \mathrm{CFU} / \mathrm{mL}$ (CFU, colony forming units) in Muller Hinton II broth (MHB-II; Liofilchem, Italy). The bac- teria were treated with 1018-K6 (ranging from 0.156 to $80 \mu \mathrm{M}$ ) in $100 \mu \mathrm{L}$ culture medium (MHB-II) for $16 \mathrm{~h}$ at $37^{\circ} \mathrm{C}$. The cell growth was measured by the absorbance at $620 \mathrm{~nm}$ in a microplate reader (Victor, PerkinEImer, Waltham, MA). The MIC is defined as the lowest con- centration of the peptide at which no bacterial growth was detected. To determine the MBC, $50 \mu \mathrm{L}$ of the bacterial cell suspension was taken based on the MICs and cultivated on a Tryptic Soy Agar (TSA) plates. The bacterial cells were enumerated after incubation at $37^{\circ} \mathrm{C}$ for 24-48 h. MBCs is defined as the lowest concentration of peptide at which more than $99.9 \%$ of the bacterial cells are killed. At least six technical replicates were included for each group, and all experiments were performed in triplicate.

\section{Inhibition of biofilm formation}

The ability of 1018-K6 to prevent biofilm formation was evaluated in 96-wells flat bottom polystyrene microtiter plates (SPL Life Sciences, Korea). Biofilms were allowed to form in absence or in presence of 1018-K6, according to a previously described method (Stepanović et al., 2007), with slight modifications. Briefly, $200 \mu \mathrm{L}$ of S. aureus ATCC 35556, MRSA ATCC 33591, or SA1 bacterial cultures, serially diluted to $5 \times 106 \mathrm{CFU} / \mathrm{mL}$ in TSB, were distributed in each well of the microtiter plates and the peptide was added in order to reach the concentration of $80 \mu \mathrm{M}$. Plates were incubated at $37^{\circ} \mathrm{C}$ for $24 \mathrm{~h}$. After incubation, the supernatant was discarded and each well was washed three times with $300 \mu \mathrm{L}$ of sterile PBS. The remaining bacteria were heat-fixed $\left(60^{\circ} \mathrm{C}\right.$,

$60 \mathrm{~min}$ ) and stained with $150 \mu \mathrm{L}$ of $2 \%$ crystal violet (Conda labora-

tories, Madrid, Spain) for 20 min. After staining, bacteria were rinsed under running tap water. Therefore, the microplate was air dried at room temperature, and the dye bound to the cells was resolubilized with $150 \mu \mathrm{L}$ of $95 \%$ ethanol (Carlo Erba reagents, Milan, Italy) per well. The optical density (OD) of each well stained with crystal violet was measured at $540 \mathrm{~nm}$ using a microtiter-plate reader (Victor, Perki- nElmer, Waltham, MA). At least six technical replicates were included for each group, and all experiments were performed in triplicate. Ac- cording to the OD values of negative controls, the cutoff value (ODc) was established as follow: ODmean +3 * St. deviation. The OD value of a tested condition (control, 1018-K6 treated) is expressed as OD mean value of the condition reduced by ODc value.

\section{Minimum biofilm eradication concentration determination}

Minimum biofilm eradication concentration (MBEC) assay was used to test susceptibility of the pre-formed S. aureus ATCC 35556, MRSA ATCC 33951, or SA1 biofilms to 1018-K6 (Ceri et al., 2001). Briefly, $150 \mu \mathrm{L}$ of bacterial cultures diluted to $105 \mathrm{CFU} / \mathrm{mL}$ were added to the wells of 96-wells flat-bottom microtiter plates (Nunc, Roskilde, Den- mark). Then, plates were covered with a 96-peg lid (Immuno TSP lids; Nunc, Roskilde, Denmark), sealed with Parafilm ${ }^{\circledR}$, and placed on an microtiter shaker (MTS 2/4 digital microtiter shaker, IKAWorks, Staufen im Breisgau, Germany), set to 150 revolutions per min (rpm), in a humidified atmosphere (40\%) at $37^{\circ} \mathrm{C}$ (G-Cell 115, Fratelli Galli, Milan, Italy) for $24 \mathrm{~h}$, to allow biofilm formation on the pegs under batch conditions. Subsequently, planktonic bacteria were removed by rinsing the peg lid in $200 \mu \mathrm{L}$ of sterile PBS. Biofilms on the pegs were exposed to $1018-\mathrm{K} 6(0.25-80 \mu \mathrm{M})$ in $200 \mu \mathrm{L}$ PBS for $24 \mathrm{~h}$ at $37^{\circ} \mathrm{C}$. After exposure, the peg lid was rinsed, as described previously, for $1 \mathrm{~min}$, and then transferred to a new microtiter plate containing $200 \mu \mathrm{L} /$ well of fresh TSB and sonicated for $15 \mathrm{~min}$ (Ultrasonik 57H; NEY, USA), 
in order to disperse the cells from the peg surface (recovery plate). After sonication, an aliquot $(50 \mu \mathrm{L})$ was used for preparing serial dilutions that were spot plated $(20 \mu \mathrm{L})$ on TSA. The peg lid was then discarded and the recovery plate was covered with a normal lid and incubated for $24 \mathrm{~h}$ at $37{ }^{\circ} \mathrm{C}$. The MBEC is defined as the lowest concentration of 1018- K6 required to eradicate the biofilm of a selected isolate after a recovery period of $24 \mathrm{~h}$ at 37 ${ }^{\circ} \mathrm{C}$. At least four technical replicates were included for each group, and all experiments were performed in triplicate.

\section{Biofilm eradication assay}

Biofilm eradication was assayed using the previously described protocol. Briefly, $150 \mu \mathrm{L}$ inoculum of S. aureus ATCC 35556, MRSA ATCC 33591, and SA1 were prepared at 105 $\mathrm{CFU} / \mathrm{ml}$ concentration. Biofilms were grown for $24 \mathrm{~h}$ at $37^{\circ} \mathrm{C}, 150 \mathrm{rpm}$, on TSP peg lid. Then, cells were exposed to 1018-K6 $(80 \mu \mathrm{M})$ at different times of contact ranging from 1 min to $48 \mathrm{~h}$ at $37^{\circ} \mathrm{C}$. Cells were recovered in fresh TSB by sonication at room temperature for $15 \mathrm{~min}$. An aliquot from each well was spot plated on TSA, then the microtiter plate was incubated at $37^{\circ} \mathrm{C}$ for $24 \mathrm{~h}$. Following incubation, OD was detected using a micro- titer-plate reader (Victor, PerkinElmer, Waltham, MA). Cells spot plated were counted after $24 \mathrm{~h}$ incubation at $37^{\circ} \mathrm{C}$. Log10 CFU/peg was cal- culated as follow: Log10 [(X-B-1) (D)+1], where $X$ is CFU counted on spot plate, $B$ is the volume plated, and $D$ is the dilution. At least six technical replicates were included for each group, and all experiments were performed in triplicate.

\section{Circular dichroism spectroscopy}

The secondary structure of the peptides was investigated by circular dichroism spectroscopy (CD) using a Jasco J-810 spectropolarimeter (Tokyo, Japan). The peptide samples at different concentrations (40,60 and $80 \mu \mathrm{M}$ in PBS) were loaded into a quartz cuvette of 0.1 $\mathrm{cm}$ path length (Hellma Analytics, Milan, Italy) and the spectra were recorded at $25^{\circ} \mathrm{C}$ in the $190 \mathrm{~nm}-260 \mathrm{~nm}$ range at $20 \mathrm{~nm} / \mathrm{min}$ scanning speed, by averaging 5 scans and in presence of $3 \mathrm{mM}$ SDS as membrane-mi- micking environment. To analyze the circular dichroism spectra ob- tained under the different experimental conditions, the relative con- tribution of three secondary structure elements ( $\alpha$-helix, $\beta$-structure and random coil) to the overall structure of the peptide was estimated by the DICHROWEB site (Lobley, Whitmore, \& Wallace, 2002; Whitmore \& Wallace, 2004, 2008), using the CDSSTR algorithm (Sreerama \& Woody, 2000; van Stokkum, Spoelder, Bloemendal, van Grondelle, \& Groen, 1990) and the BeStSel (Beta Structure Selection) web server, which is freely accessible at http://bestsel.elte.hu/index. php (Micsonai et al., 2018).

\section{Scanning electron microscopy}

Three-dimensional architecture of S. aureus ATCC 35556 biofilms exposed to 1018-K6 was studied by using the scanning electron mi- croscope (SEM). Biofilms were grown for $24 \mathrm{~h}$ and then exposed to $1018-\mathrm{K} 6(80 \mu \mathrm{M})$, as previously described, for $16 \mathrm{~h}$ at $37^{\circ} \mathrm{C}$. Pegs were removed from TSP lid using a flamed sterilized blade, and cells were fixed with $2.5 \%$ glutaraldehyde (Polysciences Inc., Warrington, PA, USA) in PBS at $4^{\circ} \mathrm{C}$ for $16 \mathrm{~h}$. Samples were washed three times with PBS (5 min each) and dehydrated at room temperature through a series of alcohol (50\%-99\% ethanol; Carlo Erba reagents, Milan, Italy). Samples were left to dry in a fume hood for $72 \mathrm{~h}$, then were sputter-coated with a gold-palladium layer using a SCD 040 coating device (Balzer Union, Liechtenstein). Samples were observed using a Zeiss DSM 950 scanning electron microscope at an accelerating voltage of $10 \mathrm{kV}$ 
(Zeiss, Oberkochen, Germany). The images were processed for display using Photoshop (Adobe Systems Inc., San Jose, CA).

\section{Statistical analysis}

Statistical analyses were carried out using GraphPad Prism version 7.04 for Windows (GraphPad Software, La Jolla California USA, www. graphpad.com). Rate of biofilm inhibition (OD540nm mean) for each strain were examined using unpaired t-test. Rate of biofilm eradication (biofilm viable count (Log10 CFU/peg) at each time point) for each strain were examined using a Kruskall-Wallis test, with a Dunn's post- hoc test used to identify individual differences relative to the untreated control (PBS) for each strain at each time point. In all cases, significance was denoted with a probability of $p<0.05$.

\section{Results and discussion}

Antimicrobial activity of 1018-K6 on planktonic S. aureus cells

The MIC values of 1018-K6 against planktonic S. aureus strains were first determined. Overall, 1018-K6 managed to inhibit the growth of the two reference $S$. aureus strains, MSSA ATCC 35556 and MRSA ATCC 33591, as well as that of the wild SA1 strain, with MIC values of $20 \mu \mathrm{M}$. To investigate further the bactericidal activity of the peptide, the MBC was evaluated. Specifically, the MBC was found to be $20 \mu \mathrm{M}$, a value that was on a par with the corresponding $\mathrm{MIC}$, thus indicating that the tested compound should be considered to have bactericidal mode of action against S. aureus ATCC 35556, MRSA ATCC 33591 and SA1 cells. In addition, a comparison between 1018-K6 and the parent peptide IDR-1018 revealed that the MIC value of the AMP used in this study was half the concentration required by IDR-1018 to completely inhibit the growth of a MRSA strain (i.e., $40 \mu \mathrm{M}$ ), as reported by de la Fuente- Núñez et al. (2014), showing an improvement in cell-inhibiting performance of the modified peptide 1018-K6.

\section{Evaluation of the activity of 1018-K6 against biofilm formation of S. aureus}

Considering the difficulty of treating contaminations associated with staphylococcal biofilms, we decided to test the ability of 1018-K6 to prevent biofilm formation. To this aim, the three strains included in this study were cultured in planktonic form in absence or presence of a peptide concentration of $80 \mu \mathrm{M}$. As shown in Fig. 1, the biomass quantification confirmed the strong capacity of the two reference strains (MSSA ATCC 35556 and MRSA ATCC 33591 ) to produce bio- film, as well as the moderate biofilm formation ability of the enterotoxigenic SA1. Interestingly, a striking ability of 1018-K6 to reduce the biofilm biomass of all the $\mathrm{S}$. aureus strains was observed compared to control cells incubated in medium without 1018-K6 (unpaired t-test; $p<0.0001$ ). The peptide successfully inhibited biofilm formation in each of these strains as confirmed by the $O D$ values of the treated bacteria which were all below the OD cutoff (ODc) defining biofilm formation, thus revealing a strong anti-biofilm impact of 1018-K6 on the tested foodborne pathogens. Indeed, further investigations clearly suggested that a peptide concentration of at least $80 \mu \mathrm{M}$ was needed to completely prevent the biofilm formation by all the strains of interest (data not shown).

\section{Minimum biofilm eradication concentration (MBEC) determination}

An important goal in the treatment of biofilm is to explore the po- tential application of AMPs in the eradication of biofilms. Indeed, it is considered that sessile cells are usually more 
resistant to antimicrobials with respect to their planktonic counterparts (Høiby, Bjarnsholt, Givskov, Molin, \& Ciofu, 2010), because mature biofilms are sur- rounded and protected by the components of the extracellular matrix, such as DNA, polysaccharides, proteins, and others (Flemming \& Wingender, 2010). In this context, the obtained results showed that a complete S. aureus ATCC 35556 biofilm eradication by $1018-\mathrm{K} 6$ was reached when the peptide was used at a concentration of $80 \mu \mathrm{M}$, even if

a concentration equal to twice $(40 \mu \mathrm{M})$ its $\mathrm{MIC}$ resulted in a 1.7

Log10 CFU/peg reduction of biofilm biomass. Similarly, also MRSA ATCC 33591 and SA1 biofilms were totally eradicated using the peptide at $80 \mu \mathrm{M}$.

Differently from the previous findings on the ability of 1018-K6 to

inhibit L. monocytogenes biofilm formation (Palmieri et al., 2018), our study evaluated, for the first time, the eradication activity of this pep- tide against established biofilms. Therefore, 1018-K6 not only con- firmed its capability to inhibit biofilm formation, but it also showed a strong eradicating activity against staphylococcal biofilms.

\section{Kinetic of action of 1018-K6 against established biofilms of S. aureus}

Changing in the amount of biomass during the peptide treatment were further examined. As reported in Fig. 2, S. aureus MSSA ATCC 35556, MRSA ATCC 33591, and SA1 cell densities in the biofilms were reduced already after 1 min of exposure. Specifically, a complete dis- ruption in biofilm cell surfaces after 5 min was observed in the case of MSSA ATCC 35556 and SA1, indicating a rapid and substantial killing efficacy of 1018-K6 ( $p<$ 0.0001 ). On the other hand, although a sig- nificant reduction of live cells (almost $50 \%, p=$ 0.0015 ) in the MRSA ATCC 33591 biofilms was observed after $5 \mathrm{~min}$, the complete biofilm eradication occurred after 15 min of peptide exposure $(p<0.0001)$. Finally, no viable cells were detected from $30 \mathrm{~min}$ to $48 \mathrm{~h}$ incubation in any conditions under investigation.

These results revealed that 1018-K6 was able to remove biofilm cells within 15 min, displaying a remarkable and rapid anti-biofilm activity against the tested biofilm producer strains. These findings are quite relevant as it has been found that staphylococci possess genetic in- formation for the resistance to antimicrobial peptides (Joo \& Otto, 2015), since they have developed different molecular mechanisms in- volved in the prevention of AMP action during both contamination and infection (Peschel \& Sahl, 2006). Such mechanisms - that are controlled by specific sensor/regulator systems and that include surface charge alteration, extracellular proteases, exopolymers, and efflux pump pro- teins (Joo \& Otto, 2015) - could also contribute to the different sus- ceptibility of the tested strains in the response to the peptide.

The results achieved in this study are very impressive in terms of rate of action of the peptide on existing biofilms. Specifically, AMPs so far studied showed the ability to eradicate established biofilms after longer times of exposure (e.g., $6 \mathrm{~h}$ of treatment; Laverty, McCloskey, Gorman, \& Gilmore, 2015). Therefore, to the best of our knowledge, this is the first report concerning the effects of an AMP such as 1018-K6 against established biofilms of pathogenic bacteria within few minutes, which pointed out a very rapid mechanism of action. For this reason, we hypothesized that 1018-K6 could kill bacteria in a way that not necessary involves an intracellular response messenger, as this strategy would require a time-period longer than minutes to work.

\section{Structural characterization of 1018-K6}

Previous studies have indicated that the interactions of AMPs with membrane components should result in conformational changes of the peptide (Palmieri et al., 2016; Pasupuleti, Walse, Svensson, Malmsten, \& Schmidtchen, 2008; Yang et al., 2018; Zelezetsky \& Tossi, 
2006). Therefore, $C D$ spectroscopic measurements as function of the peptide concentration, were applied to examine the secondary structure of 1018-K6 and evaluate the correlation between the 1018-K6 conforma- tional changes and the antimicrobial/anti-biofilm activities of the peptide against $\mathrm{S}$. aureus. The results clearly demonstrated that 1018-K6 adopted ahelix/ $\beta$-sheet mixed conformations in micellar buffer solu- tion, which remained preserved in the concentration range tested up to $48 \mathrm{~h}$ (Fig. 3). Specifically, by using a recently developed web server called BeStSel, a more accurate estimation of the secondary structure composition of the 1018-K6 peptide, has been performed from CD spectra. Indeed, the prediction of $\beta$-sheet-rich or $\alpha / \beta$-mixed structures has proven to be difficult and biased due to their spectral variety and lower spectral amplitudes (Greenfield, 2006) and this is assumed to be an intrinsic limitation of CD spectroscopy (Khrapunov, 2009). There- fore, BeStSel improves the accuracy and increases the information re- lated to the secondary structure prediction better than any other pre- viously published algorithms (Micsonai et al., 2018). As shown in Fig. 3, an improvement in the percentage content of $\beta$-helix conformation, which paralleled to a decrease of the random coil structures, was observed by increasing the peptide concentration. In Fig. 4, these structural data are better highlighted and the information obtained by CD spectroscopy at the extreme of concentrations used ( $40-80 \mu \mathrm{M})$ and $48 \mathrm{~h}$ incubation time were compared. The CD spectra obtained at the two concentrations showed noticeable differences in the relative con- tent of the secondary structures. In the table included in Fig. 4, the values of the eight components of secondary structure contents, as determined with the BeStSel server, were showed and the data were plotted in a pie chart graphic for an easier display. Thus, the variations in the far-UV CD signals were attributed to the structural rearrange- ments in the peptide molecule when analyzed at different concentra- tions, suggesting that 1018-K6 underwent to conformational changes with a high tendency to preserve a well-organized structure. Interest- ingly, the folded condition remained stable at increasing concentrations with the rate of $\alpha$-elements substantially unchanged and a conversion of the total content of $\beta$-parallel to antiparallel elements. Results revealed (Supplementary Table 1) that 1018-K6 displayed a general $\alpha / \beta$ mixed structure, which appeared unchangeable both as function of peptide concentration and incubation time. Therefore, BeStSel resulted to be more suitable to predict any conformational changes of peptides in the presence of $\alpha / \beta$-mixed folding as for $1018-\mathrm{K} 6$. Finally, the CD experiments could suggest that $1018-\mathrm{K} 6$ at in- creasing concentrations undergoes intermolecular interactions assisted via a spontaneously self-organization, which arise by the strong ten- dency to assume $\beta$-sheet conformations (Gambaretto, Tonin, Di Bello, \& Dettin, 2008). On this basis, it could be hypothesized that the strongest anti-biofilm effect exhibited by $1018-\mathrm{K} 6$ against $\mathrm{S}$. aureus at $80 \mu \mathrm{M}$ was correlated to a possibly selfassembly process, which can be critical to affect the $\mathrm{S}$. aureus biofilm stability and its architecture.

\section{Scanning electron microscopy analysis of 1018-K6 effects on S. aureus biofilms}

Numerous antibacterial peptides kill bacteria predominantly via membrane permeabilization and subsequent structural disruption, due to their amphiphilic properties, which render them able to easily insert into the membranes of bacteria (Batoni, Maisetta, \& Esin, 2016; Brogden, 2005). As shown in Fig. 5, control biofilms (in the absence of peptide) were uniform and firmly attached, with a continuous, ex- tensive and interconnected network of cells and exopolymeric matrix materials. In addition, control pegs resulted covered by multilayered and three-dimensional structures of sessile cells. In contrast, 1018-K6 exposure induced a significant membrane damage within $16 \mathrm{~h}$ treat- ment. Indeed, detached chunks of floating matrix material and cells in discontinuous clumps were visible, together with small 
aggregates of cells presenting blebbing on the membrane surface (Fig. 6), visibly in- dicating a significant destabilization and impairment of the cell mem- brane structure. Therefore, the modification of bacterial morphology induced by 1018-K6 suggested that the mode of action of the peptide can be directed to the cell-envelope, rather than to intracellular mes- sengers involved in biofilm formation.

\section{Conclusions}

The present study aimed at investigating the bactericidal efficiency of a novel IDR-1018derived peptide, named 1018-K6, against plank- tonic and biofilm-embedded $\mathrm{S}$. aureus ATCC 35556 and MRSA ATCC 33591 cells, as well as against a food isolated enterotoxigenic strain (SA1). The results achieved demonstrated that 1018-K6 was able to cause a fast and complete killing of staphylococcal biofilms within the first 15 min, as well as to fully prevent biofilm formation, displaying also a potent bactericidal activity against planktonic cells. Interestingly, the antimicrobial and anti-biofilm action of the peptide was observed not only on the reference strains deriving from ATCC collection, but also on a wild strain isolated from a food product (i.e., cheese) that carried the genes encoding for different SEs, indicating efficacy and potential utility of this peptide in the control of food-related S. aureus strains.

In addition, after treatment of the reference strain MSSA ATCC 35556 with supra-MIC concentrations of $1018-\mathrm{K} 6$, several distinct signs of damage to the cell envelope were evident in the SEM micrographs, such as membrane wrinkling and multiple blebbing. These results could support a direct cell membrane-affecting mode of action of 1018-K6, not involving the interaction and inhibition of intracellular messengers of biofilm. These features represent an advantage for several bio- technological applications, as the membraneaffecting antimicrobials exhibit a rapid and broad-spectrum activity and a low propensity to develop antibiotic-resistance.

Finally, the antimicrobial and anti-biofilm activities, as well as the reliable modus operandi together with the uncommon stability at dif- ferent temperature (i.e. 15 and $90{ }^{\circ} \mathrm{C}$ ) and $\mathrm{pH}$ conditions and the scarce tendency to precipitate in aqueous solutions, make 1018-K6 a good candidate for industrial uses such as the implementation of "green" packaging technologies and bio-sanitizing formulations. Further studies will be necessary to better evaluate 1018-K6 performances both in free- or bound-form against clinical and environmental isolates of pathogenic and spoiler bacteria.

\section{References}

Batoni, G., Maisetta, G., \& Esin, S. (2016). Antimicrobial peptides and their interaction with biofilms of medically relevant bacteria. Biochimica et Biophysica Acta (BBA) Biomembranes, 1858(5), 1044-1060. https://doi.org/10.1016/J.BBAMEM.2015.10.

013.

Bechinger, B., \& Gorr, S.-U. (2017). Antimicrobial peptides: Mechanisms of action and resistance. Journal of Dental Research, 96(3), 254-260. https://doi.org/10.1177/ 0022034516679973.

Brogden, K. A. (2005). Antimicrobial peptides: Pore formers or metabolic inhibitors in bacteria? Nature Reviews Microbiology, 3(3), 238-250. https://doi.org/10.1038/ nrmicro1098.

Ceri, H., Olson, M., Morck, D., Storey, D., Read, R., Buret, A., et al. (2001). The MBEC assay system: Multiple equivalent biofilms for antibiotic and biocide susceptibility testing. Methods in Enzymology, 337, 377-385. https://doi.org/10.1016/S0076- 6879(01)37026-X. 
CLSI (2015). Methods for dilution antimicrobial susceptibility tests for bacteria that grow aerobically. Approved standard-tenth edition. CLSI document M07-A10. https://doi.org/ 10.4103/0976-237X.91790.

Di Ciccio, P., Vergara, A., Festino, A. R., Paludi, D., Zanardi, E., Ghidini, S., et al. (2015). Biofilm formation by Staphylococcus aureus on food contact surfaces: Relationship with temperature and cell surface hydrophobicity. Food Control, 50, 930-936. https://doi.org/10.1016/j.foodcont.2014.10.048.

Flemming, H. C., \& Wingender, J. (2010). The biofilm matrix. Nature Reviews Microbiology, 8(9), 623-633. https://doi.org/10.1038/nrmicro2415.

de la Fuente-Núñez, C., Korolik, V., Bains, M., Nguyen, U., Breidenstein, E. B. M., Horsman, S., et al. (2012). Inhibition of bacterial biofilm formation and swarming motility by a small synthetic cationic peptide. Antimicrobial Agents and Chemotherapy, 56(5), 2696-2704. https://doi.org/10.1128/AAC.00064-12.

de la Fuente-Núñez, C., Reffuveille, F., Haney, E. F., Straus, S. K., \& Hancock, R. E. W. (2014). Broad-spectrum anti-biofilm peptide that targets a cellular stress response. PLoS Pathogens, 10(5), e1004152. https://doi.org/10.1371/journal.ppat.1004152.

Gambaretto, R., Tonin, L., Di Bello, C., \& Dettin, M. (2008). Self-assembling peptides: Sequence, secondary structure in solution and film formation. Biopolymers, 89, 906-915. https://doi.org/10.1002/bip.21030.

Gowrishankar, S., Kamaladevi, A., Balamurugan, K., \& Pandian, S. K. (2016). In vitro and in vivo biofilm characterization of Methicillin-Resistant Staphylococcus aureus from patients associated with pharyngitis infection. BioMed Research International, 1289157. $2016 \mathrm{https}: / /$ doi.org/10.1155/2016/1289157.

Grace, D., \& Fetsch, A. (2018). Staphylococcus aureus-a foodborne pathogen: Epidemiology, detection, characterization, prevention, and control: An overview. In

A. Fetsch (Ed.). Staphylococcus aureus (pp. 3-10). Academic Press. https://doi.org/10. 1016/B978-0-12-809671-0.00001-2.

Greenfield, N. J. (2006). Using circular dichroism spectra to estimate protein secondary structure. Nature Protocols, 1, 2876-2890. https://doi.org/10.1038/nprot.2006.202. Gutiérrez, D., Delgado, S., Vázquez-Sánchez, D., Martínez, B., Cabo, M. L., Rodríguez, A., et al. (2012). Incidence of Staphylococcus aureus and analysis of associated bacterial communities on food industry surfaces. Applied and Environmental Microbiology, 78(24), 8547-8554. https://doi.org/10.1128/AEM.02045-12.

Hennekinne, J. A. (2018). Staphylococcus aureus as a leading cause of foodborne outbreaks worldwide. Staphylococcus aureus (pp. 129-146). Cambridge, Massachusetts: Academic Press. https://doi.org/10.1016/B978-0-12-809671-0.00007-3.

Hennekinne, J. A., De Buyser, M. L., \& Dragacci, S. (2012). Staphylococcus aureus and its food poisoning toxins: Characterization and outbreak investigation. FEMS Microbiology Reviews, 36(4), 815-836. https://doi.org/10.1111/j.1574-6976.2011. 00311.x.

Høiby, N., Bjarnsholt, T., Givskov, M., Molin, S., \& Ciofu, O. (2010). Antibiotic resistance of bacterial biofilms. International Journal of Antimicrobial Agents, 35(4), 322-332. https://doi.org/10.1016/J.IJANTIMICAG.2009.12.011.

Joo, H. S., \& Otto, M. (2015). Mechanisms of resistance to antimicrobial peptides in staphylococci. Biochimica et Biophysica Acta, 1848(11 Pt B), 3055-3061. https://doi. org/10.1016/j.bbamem.2015.02.009.

Keymanesh, K., Soltani, S., \& Sardari, S. (2009). Application of antimicrobial peptides in agriculture and food industry. World Journal of Microbiology and Biotechnology, 25(6), 933944. https://doi.org/10.1007/s11274-009-9984-7.

Khrapunov, S. (2009). Circular dichroism spectroscopy has intrinsic limitations for pro- tein secondary structure analysis. Analytical Biochemistry, 389, 174-176. https://doi. org/10.1016/j.ab.2009.03.036. 
Laverty, G., McCloskey, A. P., Gorman, S. P., \& Gilmore, B. F. (2015). Anti-biofilm activity of ultrashort cinnamic acid peptide derivatives against medical device-related pa- thogens. Journal of Peptide Science, 21(10), 770-778. https://doi.org/10.1002/psc. 2805.

Lobley, A., Whitmore, L., \& Wallace, B. A. (2002). DICHROWEB: An interactive website for the analysis of protein secondary structure from circular dichroism spectra.

Bioinformatics, 18(1), 211-212. https://doi.org/10.1093/bioinformatics/18.1.211. Mansour, S. C., de la Fuente-Núñez, C., \& Hancock, R. E. W. (2015). Peptide IDR-1018:

Modulating the immune system and targeting bacterial biofilms to treat antibiotic- resistant bacterial infections. Journal of Peptide Science, 21(5), 323-329. https://doi. org/10.1002/psc.2708.

Micsonai, A., Wien, F., Bulyáki, É., Kun, J., Moussong, É., Lee, Y. H., et al. (2018). BeStSel: A web server for accurate protein secondary structure prediction and fold recognition from the circular dichroism spectra. Nucleic Acids Research, 6(W1), W315-W322. https://doi.org/10.1093/nar/gky497.

Palmieri, G., Balestrieri, M., Capuano, F., Proroga, Y. T. R., Pomilio, F., Centorame, P., et al. (2018). Bactericidal and antibiofilm activity of bactenecin-derivative peptides against the food-pathogen Listeria monocytogenes: New perspectives for food proces- sing industry. International Journal of Food Microbiology, 279, 33-42. https://doi.org/ 10.1016/J.IJFOODMICRO.2018.04.039.

Palmieri, G., Balestrieri, M., Proroga, Y. T. R., Falcigno, L., Facchiano, A., Riccio, A., et al. (2016). New antimicrobial peptides against foodborne pathogens: From in silico de- sign to experimental evidence. Food Chemistry, 211, 546-554. https://doi.org/10. 1016/j.foodchem.2016.05.100.

Pasupuleti, M., Walse, B., Svensson, B., Malmsten, M., \& Schmidtchen, A. (2008). Rational design of antimicrobial $\mathrm{C} 3 a$ analogues with enhanced effects against staphylococci using an integrated structure and function-based approach. Biochemistry, 47, 9057-9070. https://doi.org/10.1021/bi800991e.

Peschel, A., \& Sahl, H.-G. (2006). The co-evolution of host cationic antimicrobial peptides and microbial resistance. Nature Reviews Microbiology, 4(7), 529-536. https://doi. org/10.1038/nrmicro1441.

Reffuveille, F., de la Fuente-Núñez, C., Mansour, S., \& Hancock, R. E. W. (2014). A broadspectrum antibiofilm peptide enhances antibiotic action against bacterial biofilms. Antimicrobial Agents and Chemotherapy, 58(9), 5363-5371. https://doi.org/10.1128/ AAC.03163-14.

Sreerama, N., \& Woody, R. W. (2000). Estimation of protein secondary structure from circular dichroism spectra: Comparison of CONTIN, SELCON, and CDSSTR methods with an expanded reference set. Analytical Biochemistry, 287(2), 252-260. https:// doi.org/10.1006/abio.2000.4880.

Stepanović, S., Vuković, D., Hola, V., Di Bonaventura, G., Djukić, S., Ćirković, I., et al. (2007). Quantification of biofilm in microtiter plates: Overview of testing conditions and practical recommendations for assessment of biofilm production by staphylo- cocci. Acta Pathologica, Microbiologica et Immunologica Scandinavica, 115(8), 891-899. https://doi.org/10.1111/j.1600-0463.2007.apm_630.x.

van Stokkum, I. H. M., Spoelder, H. J. W., Bloemendal, M., van Grondelle, R., \& Groen, F. C. A. (1990). Estimation of protein secondary structure and error analysis from cir-cular dichroism spectra. Analytical Biochemistry, 191(1), 110-118. https://doi.org/ 10.1016/00032697(90)90396-Q.

Thompson, K. M., Abraham, N., \& Jefferson, K. K. (2010). Staphylococcus aureus extracellular adherence protein contributes to biofilm formation in the presence of serum. FEMS Microbiology Letters, 305(2), 143-147. https://doi.org/10.1111/j.1574-6968. 2010.01918.x. 
Wang, S., Zeng, X., Yang, Q., \& Qiao, S. (2016). Antimicrobial peptides as potential alternatives to antibiotics in food animal industry. International Journal of Molecular Sciences, 17(5), 603. https://doi.org/10.3390/ijms17050603.

Whitmore, L., \& Wallace, B. A. (2004). DICHROWEB, an online server for protein secondary structure analyses from circular dichroism spectroscopic data. Nucleic Acids Research, W32, W668-W673. https://doi.org/10.1093/nar/gkh371.

Whitmore, L., \& Wallace, B. A. (2008). Protein secondary structure analyses from circular dichroism spectroscopy: Methods and reference databases. Biopolymers, 89(5), 392-400. https://doi.org/10.1002/bip.20853.

World Health Organization (2015). Fact sheet № 399 - food safety. Retrieved from http:// www.who.int/mediacentre/factsheets/fs399/en/.

Yang, C. H., Chen, Y. C., Peng, S. Y., Tsai, A. P. Y., Lee, T. J. F., Yen, J. H., et al. (2018). An engineered arginine-rich a-helical antimicrobial peptide exhibits broad-spectrum bactericidal activity against pathogenic bacteria and reduces bacterial infections in mice. Scientific Reports, 8, 14602-14607. https://doi.org/10.1038/s41598-01832981-3.

Zelezetsky, I., \& Tossi, A. (2006). Alpha-helical antimicrobial peptides-using a sequence template to guide structure-activity relationship studies. Biochimica et Biophysica Acta (BBA) - Biomembranes, 1758(9), 1436-1449. https://doi.org/10.1016/J.BBAMEM. 2006.03.021. 